\title{
ANTIEPILEPTIC DRUGS, FOETAL MALFORMATIONS, and SPONTANEOUS ABORTIONS
}

F J E Vajda ${ }^{1}$, T J O’Brien ${ }^{1}$, J E Graham ${ }^{1}$, A A Hitchcock ${ }^{1}$, C M Lander ${ }^{2}$, M J Eadie ${ }^{2}$

-

${ }^{1}$ Department of Medicine and Neurosciences, Royal Melbourne Hospital and University of Melbourne, Parkville, Victoria, 3050,

2 Royal Brisbane and Women's Hospital and School of Medicine and Biomedical Science, University of Queensland, Brisbane, Queensland, 4027.

\section{Corresponding Author:}

Professor FJE Vajda

Address: Department of Medicine and Neurosciences, Royal Melbourne Hospital and University of Melbourne, Parkville, Australia 3050

Telephone: 61(3).98193056

E-mail: vajda@netspace.net.au

Word Count: 2867 in main text - plus 3 Tables, no Figures

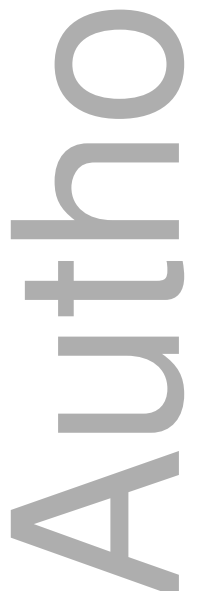

\section{Running title:Antiepileptic drugs, malformations and miscarriages}

This is the author manuscript accepted for publication and has undergone full peer review but has not been through the copyediting, typesetting, pagination and proofreading process, which may lead to differences between this version and the Version of Record. Please cite this article as doi: $10.1111 /$ ANE.12672

This article is protected by copyright. All rights reserved 
Received Date : 12-Jul-2016

Revised Date : 08-Aug-2016

Accepted Date : 12-Aug-2016

Article type : Original Article

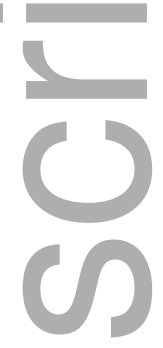

ABSTRACT

Background: Some recent studies have found an association between foetal malformations in earlier antiepileptic drug (AED) exposed pregnancies and an increased hazard of such malformations in subsequent pregnancies. We investigated this matter further, and also considered the possible role of spontaneous abortions in previous pregnancies, in this situation.

Methods: Analysis of foetal malformation data for current and previous pregnancies in women taking AEDs and women with untreated epilepsy in the Australian Register of Antiepileptic Drugs in Pregnancy (APR).from 1999 to late 2014.

Results: AED treated women with either a malformed foetus or a spontaneous abortion in their previous pregnancy had a statistically significant 2 to 3 -fold increased risk of foetal malformation in their next pregnancy, compared with similarly treated women with normal offspring in their previous pregnancy. This was not seen in the same circumstances in women with untreated epilepsy. On AED treatment, the women were more likely to have spontaneous abortions than in their previous untreated pregnancies. Possibly some of the increased abortion rate resulted from drug-related malformations that were incompatible with continuing intrauterine survival.

Conclusions: In assessing the hazard of an AED treated woman having a malformed foetus, it is important to know both the AEDs being taken and,, if there had been a previous pregnancy, whether a foetal malformation or a spontaneous abortion occurred in it. 
Key Words: abortion, antiepileptic drug, foetus, malformations, miscarriage

\section{INTRODUCTION}

Considerable information is available concerning the hazard of human foetal malformation associated with intrauterine exposure to various antiepileptic drugs (AEDs), particularly valproate. Much of this information has been obtained from studies that have regarded each pregnancy as a self-contained event, independent of what may have happened to the foetus in previous pregnancies. However, data from the United Kingdom and Ireland Register and the Australian Register of Antiepileptic Drugs in Pregnancy (APR) have indicated that foetal malformations in a previous pregnancy were associated with an increased chance of foetal malformations in subsequent pregnancies [1,2]. These findings were supported by an analysis of the population-based Medical Birth Registry of Norway [3\}, but not by a study based on the Kerala Registry of Epilepsy and Pregnancy [4].

Since the earlier report from the Australian Register, a larger collection of pregnancy-related information has been accumulated and analysed to try to obtain further insights into relationships between the outcomes of earlier pregnancies and the risk of AED-associated foetal malformation in subsequent pregnancies. In this analysis, the possible role of spontaneous abortion in previous pregnancies has also been investigated.

\section{MATERIALS and METHODS}

The present paper is based on data collected in the APR between 1999 and the end of 2014 . More detailed information regarding the Register and its recruitment policies and data handling practices has been published elsewhere [5,6]. In brief, the Register prospectively collects details of the pregnancies of Australian women who are taking AEDs, nearly always for the treatment of epilepsy, and women with epilepsy not taking AEDs in at least the first four months of pregnancy. Enrolment in the Register is at the discretion of individual women after referral from various professional and lay sources. During its existence, the Register has collected information on about $8.7 \%$ of the relevant pregnancies that are estimated to have occurred in Australia [7]. All participant contact with the Register is by telephone.

Information about the course of pregnancy is recorded at the initial contact, again at approximately 28 weeks of pregnancy, then within the first post-partum month and finally, as far as possible, at approximately one year after birth. Information is obtained concerning the 
current and all previous pregnancies, and AED intake. The accuracy of the information provided by pregnant women is checked with their current treating medical practitioners. However, it has not been practicable to carry out such validation regarding earlier pregnancies unless those pregnancies had previously been included in the Register. No attempt is made to influence the clinical management of the pregnancies enrolled in the Register. The Register has been under the ethics oversight of various Melbourne based institutional ethics committees, and is currently under the Human Research and Ethics Committee of Melbourne Health.

Repeated pregnancies in the same women were identified after linkage to a separate database containing the women's names and dates of birth. Relevant data from the Register were then transferred to an Excel spreadsheet and analysed statistically, mainly using logistic regression and confidence interval analysis, in particular relative risk (R.R.) calculations. Except where specified, the denominator in all foetal malformation rates that were subjected to statistical significance testing was the number of all relevant pregnancies, and included spontaneous and maternally instituted abortions and other foetal deaths.

By the end of 2014, the Register contained information collected contemporaneously with the current pregnancy in 1557 women. The data for 711 of the 1557 first pregnancies of these women were collected during these pregnancies, the remainder being obtained through retrospective inquiry. There also was information for 1110 second and third pregnancies, in 684 of them the data being collected during these pregnancies. Foetal outcome information was not available for 71 of the pregnancies, due to inability to maintain contact with women throughout pregnancy, or failure to record the use or non-use of AEDs in retrospectively obtained data. This explains apparent discrepancies between the above numbers and those in the Tables in this paper. Additionally, there were small numbers of fourth, fifth and sixth pregnancies, but for most purposes in the present study they were too few to permit reliable conclusions. In the whole database there were another 357 pregnancies that had ended in spontaneous abortion, and also a few intrauterine deaths, still births and pregnancies that had been terminated for what were categorised in the Register as maternally related indications and in which foetal normality or malformation was not recorded.

\section{RESULTS}

A preliminary screening logistic regression analysis of data for the first three pregnancies of women in the APR showed statistically significant partial regression coefficients for the 
relationship between (i) foetal malformations and exposure to valproate, but not other AEDs, in the current pregnancy, (ii) foetal malformation in the previous pregnancy and (iii) a nearly significant relationship with spontaneous abortion in the previous pregnancy. The relationship with valproate exposure is already well known and was not reinvestigated, but the relationships between foetal outcomes of previous pregnancies and malformation in subsequent pregnancies were examined further.

Table 1 shows the foetal outcomes for the first three pregnancies in women in the APR. The outcomes considered were foetal anatomical normality or malformation, spontaneous abortion (under the heading 'miscarriage'), abortion carried out for maternal reasons, and foetal deaths where foetal structural integrity was not known. For the first pregnancy, the foetal outcomes were related to whether or not there was AED exposure in the first four months of pregnancy, and also to whether or not the exposure involved valproate. For the second and third pregnancies similar data are shown, but further subdivided according to whether the previous pregnancy had yielded a normal or a malformed foetus, or had ended in a spontaneous abortion.

\section{Foetal Malformation Rates}

\section{Pregnancies with no AED exposure}

The foetal malformation rate for all pregnancies where there was no AED exposure was $2.5 \%$ (or 3.5\% for pregnancies where foetal structural normality or otherwise was known). These rates appear generally consistent with the foetal malformation rate for the general Australian population (3.1\% in 2002-2003 [8]). The foetal malformation rates were reasonably similar in Pregnancies I, II and III (2.2\%, $1.5 \%$ and $2.9 \%$, respectively), so long as the previous pregnancy, if any, had resulted in a normal foetus.

Foetal malformation in the previous pregnancy: When Pregnancy I had resulted in a malformed foetus, the malformation rates in AED-unexposed Pregnancy II was statistically significantly higher than when Pregnancy I had yielded a normal foetus (20\% v 1.0\%: R.R. $=19.60 ; 95 \%$ C.I. $=1.42,269.8)$, but the $20 \%$ rate was based on only 5 pregnancies, and should be regarded with considerable caution. There were no malformed foetuses in Pregnancy III when Pregnancy II had produced a malformed foetus. Overall there was little convincing evidence that the outcome of the previous pregnancy affected the foetal malformation outcome when neither pregnancy had been exposed to AEDs. 
Spontaneous abortion in the previous pregnancy: In AED-unexposed women, the spontaneous abortion rate in Pregnancy II was not statistically significantly higher when Pregnancy I had ended in a spontaneous abortion than when it had involved a normal foetus $(5.6 \%$ v $1.0 \%$ : R.R. $=5.5,95 \%$ C.I. $=0.36,83.99)$. The rate was lower in the same situation in Pregnancy III relative to Pregnancy II (0\% v. $2.9 \%)$.

\section{Pregnancies with AED exposure}

The malformation rate in AED-exposed Pregnancy I was statistically significantly higher than in pregnancies where there was no AED exposure $(6.7 \%$ v. $2.4 \%$; R.R. $=2.78 ; 95 \%$ C.I. $=1.30,5.95)$. The same applied for the valproate-exposed subgroup $(13.1 \% \mathrm{v} 2.4 \% ; \mathrm{R} . \mathrm{R}=$ $5.43,95 \%$ C.I. $=2.50,11.80)$.

Foetal malformation in the previous pregnancy: In AED-exposed pregnancies the malformation rate in Pregnancy II was statistically significantly greater when the foetus in Pregnancy I was malformed than when it was normal (17.4\% v 5.3\%; R.R. $=3.29$; 95\% C.I. $=$ $1.58,6.85)$. The rate also was higher, though not statistically significantly so, when Pregnancy III followed a foetal malformation in Pregnancy II, as compared with when the foetus in Pregnancy II was normal (6.9\% v 3.4\%; R.R. $=2.02 ; 95 \%$ C.I. $=0.44,9.25)$. Similar analyses for the valproate exposed subgroup for Pregnancy II yielded a higher R.R. value $(20.8 \%$ v $5.7 \%$; R.R. $=3.68,95 \%$ C.I. $=1.2,11.07)$. The numbers for valproate-exposed Pregnancy III were too small for useful analysis.

Where data in the whole APR were available for two consecutive AED treated pregnancies in the same woman, if the earlier pregnancy had resulted in a foetal malformation the malformation rate for the later pregnancy was higher than if the earlier pregnancy involved a normal foetus $(13.2 \%$ of 114 pregnancies v $5.2 \%$ of 923 pregnancies; R.R. $=2.53$; 95\% C.I. $=$ $1.47,4.37)$.

Spontaneous abortion in the previous pregnancy: For AED-exposed pregnancies, when Pregnancy I had ended in a spontaneous abortion, the Pregnancy II foetal malformation rate was higher, though not statistically significantly so, than when the foetus in Pregnancy I was normal $(11.55 \%$ v 5.3\%; R.R. $=2.18$; 95\% C.I.= 0.94, 5.06). However, the malformation rate in Pregnancy III was statistically significantly higher when Pregnancy II had resulted in a spontaneous abortion rather than a normal foetus $(9.4 \%$ v $3.4 \%$; R.R. $=2.72 ; 95 \%$ C.I $=1.02$, 7.28). 
In AED-treated women in the whole APR with at least two consecutive pregnancies, when the earlier pregnancy had resulted in a spontaneous abortion rather than a normal offspring, the malformation rate was higher in the next pregnancy (11.4\% of 336 pregnancies $v 5.2 \%$ of 923; R.R. $=2.20 ; 95 \%$ C.I. $=1.40,3.45)$.

Overall, compared with women who had carried normal foetuses in their previous pregnancies, AED treated women who had given birth to malformed foetuses, or had suffered spontaneous abortions in their previous pregnancy, appeared to have experienced a 2- to 3fold increased risk of carrying a malformed foetus in their next pregnancy.

In women who had undergone at least 3 previous pregnancies, the foetal outcomes in Pregnancy III were related to various combinations of possible foetal outcomes in the preceding two pregnancies (Table 2). Most of the malformation rates were derived from comparatively small numbers of pregnancies, and it probably is unwise to draw firm conclusions from the data, except perhaps that giving birth to a normal baby before or after a pregnancy that had ended in a spontaneous abortion may have reduced the hazard of foetal malformation occurring in the next pregnancy.

\section{Types of Malformation}

The types of malformation associated with foetal malformations or spontaneous abortions in the previous pregnancy are compared in Table 3 . There seemed to be no obvious selective association of particular types of malformation with any of the three types of pregnancy outcomes considered, but the numbers involved are probably too small to justify firm conclusions.

\section{Spontaneous Abortion Rates}

In both Pregnancies II and III in AED-unexposed women, the spontaneous abortion rate when the previous pregnancy had ended in a spontaneous abortion was higher than when the previous pregnancy had involved a normal foetus (respectively $33.3 \%$ v 9.2\%; R.R. $=4.39$, $95 \%$ C.I. $=2.04,9.46$, and $37.5 \%$ v $14.3 \%$; R.R. $=2.63,95 \%$ C.I. $=0.94,7.35)$.

In AED-treated pregnancies, in both Pregnancies II and III the spontaneous abortion rate when the previous pregnancy had ended in a spontaneous abortion also was higher than when the previous pregnancy had involved a normal foetus (respectively $25.0 \% \mathrm{v} 12.8 \%$; R.R.= $1.95 ; 95 \%$ C.I. $=1.16,3.30$, and $25.9 \%$ v $11.7 \%$; R.R. $=2.21,95 \%$ C.I. $=1.31,3.72)$. 
Spontaneous abortion rates also were a little higher in drug exposed Pregnancies II and III when the previous pregnancies had resulted in foetal malformations rather than normal offspring (respectively $17.4 \% \mathrm{v} 12.8 \%$ and $13.8 \% \mathrm{v} 11.7 \%$ ), but neither difference was statistically significant.

The spontaneous abortion rates recorded during pregnancy for the most recent pregnancies of women with more than one pregnancy in the Register appeared much lower than the rates for their previous pregnancies. This probably occurred because women tended not to enrol pregnancies as soon as they were aware of their existence, so that pregnancies ending in early spontaneous abortions were not recorded concurrently, but only in retrospect when a later pregnancy was enrolled. This phenomenon has also been noticed in relation to another pregnancy register [8]. After exclusion of the most recent pregnancy in the present data, the spontaneous abortion rate was higher in AED exposed than in untreated pregnancies $(21.4 \%$ of $1031 \mathrm{v} 14.8 \%$ of 419 ; R.R. $=1.45$; 95\% C.I. $=1.12,1.87$ ). The abortion rates were similar in both valproate-exposed pregnancies (20.7\%), and pregnancies exposed to AEDs but not valproate $(21.7 \%)$.

In the AED treated population studied, it thus seemed that a spontaneous abortion was more likely in a pregnancy that followed a spontaneous abortion than in one where the preceding pregnancy had resulted in a normal foetus, and that AED exposure increased the likelihood of spontaneous abortion in pregnancy.

\section{DISCUSSION}

An earlier study of the outcomes of the pregnancies of individual AED-treated women from the APR [2] showed that the occurrence of foetal malformation in an earlier pregnancy increased the chance of a malformation, though not necessarily the same type of malformation, occurring in the subsequent pregnancy. This was especially the case if exposure to valproate was involved. The present expanded investigation has continued to demonstrate this earlier finding, but has added to it evidence that a spontaneous abortion in the previous AED-exposed pregnancy also increases the hazard of foetal malformation occurring in the following pregnancy, more than doubling the risk. To the best of our knowledge, this association of spontaneous abortion in the preceding pregnancy with foetal malformation in the following one in AED-treated women has not been described previously. 
This increased risk seemed to apply only in pregnancies of women with epilepsy who were taking AEDs. The increased malformation hazard associated with spontaneous abortion in the previous pregnancy did not seem restricted to any particular pattern of foetal maldevelopment in the subsequent pregnancy.

Unlike the present study, which showed an increased incidence of spontaneous abortion in AED treated pregnancy, some published investigations $[9,10]$ have not found evidence of such an association. However, Tomson et al [11] found such a relationship to AED related polytherapy as compared with monotherapy, but had no untreated comparator group. In the present study the foetal malformation rate was increased in the pregnancy that follows either a spontaneous abortion or a foetal malformation, so that it seems possible that some AEDrelated spontaneous abortions represent instances of foetal malformations or tissue maldevelopment that are incompatible with continuing intrauterine existence. However, there is no direct evidence that this is the case.

The present findings have been derived from a database into which recruitment was voluntary, and into which only a minority of the probable Australian pregnancies in women with epilepsy had found their way. Therefore it is possible that the association found between foetal malformations in previous pregnancies and in a subsequent one is due to women with previous malformed foetuses tending to selectively enrol their subsequent pregnancies in the Register. If this had happened, one might have expected the foetal malformation rates in second and third pregnancies to be higher than that in first pregnancies, where the foetal structural status would usually not be know when this pregnancy was recruited into the Register. However, the malformation rates in first, second and third pregnancies were, respectively, $6.7 \%, 6.8 \%$ and $5.3 \%$, suggesting that selection bias was unlikely to have played a significant role in the present findings.

From the practical clinical viewpoint, to assess a woman's risk of having a malformed foetus associated with AED treatment in a particular pregnancy; one should know the natures and doses of any AEDs that are taken. If she has also had previous pregnancies and the most recent one while taking AEDs has resulted in a foetal malformation or a spontaneous abortion, her hazard that the next pregnancy will involve a malformed offspring is likely to be two to three times greater than it would otherwise have been.

\section{Acknowledgement}


We thank professional and lay colleagues for referring patients to the APR, and the Scientific Advisory Board and the Ethical Research Committees of St. Vincent's Hospital, Monash Medical Centre, the Royal Melbourne Hospital and other institutions for continuing ethics oversight of the APR. Over the years the Epilepsy Society of Australia, The Royal Melbourne Hospital Neuroscience Foundation, Epilepsy Australia, the NHMRC and the pharmaceutical companies Sanofi-Aventis, UCB Pharma, Janssen-Cilag, Novartis, Sci-Gen, Eisai and Genzyme have provided financial assistance to help support the Register.

\section{Disclosure of conflict of interest}

F J E Vajda has received research support for the Australian Pregnancy Register from the Epilepsy Society of Australia, RMH Neuroscience Foundation, Epilepsy Action, SanofiAventis, UCB Pharma, Eisai, and Sci-Gen.

T O'Brien has received research support from the Epilepsy Society of Australia, NHMRC, RMH Neuroscience Foundation, Sanofi-Aventis, UCB Pharma, Eisai, and Sci-Gen

C M Lander, J Graham, A Hitchcock and M J Eadie have no relevant conflicts of interest to declare.

\section{REFERENCES}

1 CAMPBELL E, DEVENNEY E, MORROW J, et al. Recurrence risk of congenital malformations in infants exposed to antiepileptic drugs in utero. Epilepsia, 2013; 54: 1665-171.

2 VAJDA FJE, O’BRIEN TJ, LANDER CM, GRAHAM J, ROTEN A, EADIE MJ Teratogenesis in repeated pregnancies in antiepileptic drug-treated women. Epilepsia 2012; 54: 181-186.

3 VEIBY G, DALTVEIT AK, ENGELSEN BA, GILHUS NE Fetal growth restriction and birth defects with newer and older antiepileptic drugs during pregnancy. J Neurol 2014; 261: $579-588$

4 BEGUM S, SARMA SP, THOMAS SV. Malformation in index pregnancy in women with epilepsy is not followed by recurrence in subsequent pregnancy. Epilepsia 2013; 54: e163-e167. 
5 VAJDA F J E, O'BRIEN T, HITCHCOCK A, GRAHAM J, LANDER C, EADIE M. The Australian antiepileptic drug in pregnancy register: Aspects of data collection and analysis. J Clin Neurosci 2007; 14:936-942.

6 VAJDA, FJE, HOLLINGWORTH S, GRAHAM J, HITCHCOCK AA, O'BRIEN, TJ, LANDER CM, EADIE MJ. Changing patterns of antiepileptic drug use in pregnant Australian women. Acta Neurol Scandinav 2010; 121: 89-93.

7 VAJDA FJE, O'BRIEN TJ, GRAHAM J, LANDER CM, EADIE MJ. The Australian register of antiepileptic drugs in pregnancy: changes over time in the epileptic population. J Clin Neurosci 2014; 21:1478-1482.

8 ABEYWARDANA S, SULLIVAN E A. Congenital anomalies in Australia 2002-2003. Sydney. AHW National Perinatal Statistics Unit. Available at http://www.npesu.unsw.edu.au/surveillance/congenital-anomalies-australia-2002-2003 on 6 August 2016.

9 MARGULIS AV, MITTLEMAN MA, GLYNN RJ, HOLMES LB, HERNÁNDEZDÍAZ S. Effeets of gestational age at enrollment in pregnancy exposure registries. Pharmacoepidemiol Drug Saf. 2015; 24:343-352.

10 ANNEGERS JF, BAUMGARTNER KB, HAUSER WA, KURLAND LT. Epilepsy, antiepileptic drugs, and the risk of spontaneous abortion. Epilepsia 1988; 29: 451-458

11 BECH BH, KJAERSGAARD MI, PEDERSEN HS et al. Use of antiepileptic drugs during pregnancy and risk of spontaneous abortion and stillbirth: population based cohort study. Brit Med J 2014; 349: g5159.

12 TOMSON T, BATTINO D, BONIZZONI E, et al. Antiepileptic drugs and intrauterine death: A prospective observational study from EURAP. Neurology 2015; 85: 580-588.

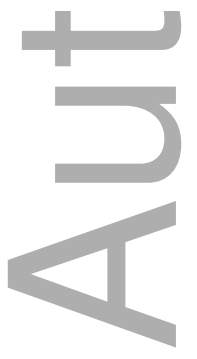


Table 1. Known foetal outcomes of Pregnancies I, II and III in women in the APR related to the foetal outcomes of the previous pregnancy in Pregnancies II and III. Except for the ' $\mathrm{N}$ ' column, all numbers in the Table are percentages. The heading 'miscarried' refers to spontaneous abortions, and 'aborted' to abortions carried out for maternally-related indications.

\begin{tabular}{|c|c|c|c|c|c|}
\hline & Normal & Malformed & Miscarried & Aborted & Died \\
\hline \multicolumn{6}{|l|}{ PREG I } \\
\hline No AEDS & 82.8 & 2.4 & 7.6 & 5.5 & 1.7 \\
\hline On AEDs & 85.5 & 6.7 & 4.4 & 2.0 & 0.6 \\
\hline -No VPA & 88.7 & 3.9 & 3.9 & 1.8 & 0.6 \\
\hline -VPA & 78.3 & 13.1 & 5.6 & 2.4 & 0.5 \\
\hline
\end{tabular}

\begin{tabular}{l|crcccr} 
PREG II & Preg I & - Normal foetus & & & & \\
No AEDS & 98 & 83.7 & $\mathbf{1 . 0}$ & 9.2 & 3.1 & 3.1 \\
On AEDs & 492 & 79.7 & $\mathbf{5 . 3}$ & 12.8 & 1.2 & 1.0 \\
-No VPA & 386 & 79.3. & $\mathbf{5 . 2}$ & 13.7 & 1.0 & 0.8 \\
-VPA & 106 & 81.1 & $\mathbf{5 . 7}$ & 9.4 & 1.9 & 1.9
\end{tabular}

\section{PREG II Preg I - Malformed foetus}

$\begin{array}{lcccccc}\text { No AEDS } & 5 & 60.0 & \mathbf{2 0 . 0} & 0 & 0 & 20 \\ \text { On AEDs } & 46 & 60.9 & \mathbf{1 7 . 4} & 17.4 & 4.3 & 0 \\ \text {-No VPA } & 22 & 68.2 & \mathbf{1 3 . 6} & 18.2 & 0 & 0 \\ \text {-VPA } & 24 & 54.2 & \mathbf{2 0 . 8} & 16.7 & 8.3 & 0\end{array}$

PREG II Preg I - Spontaneous miscarriage

$\begin{array}{lllllll}\text { No AEDS } & 18 & 61.1 & \mathbf{5 . 6} & 33.3 & 0 & 0\end{array}$




$\begin{array}{lllllll}\text { On AEDs } & 52 & 65.4 & \mathbf{1 1 . 5} & 25.0 & 0 & 0 \\ \text {-No VPA } & 35 & 68.6 & \mathbf{2 . 9} & 28.6 & 0 & 0 \\ \text {-VPA } & 17 & 52.9 & \mathbf{2 9 . 4} & 17.6 . & 0 & 0\end{array}$

\section{ron}

PREG III Preg II - Normal foetus

$\begin{array}{lrlllll}\text { No AEDS } & 35 & 82.9 & \mathbf{2 . 9} & 14.3 & 0 & 0 \\ \text { On AEDs } & 205 & 83.4 & \mathbf{3 . 4} & 11.7 & 1.5 & 0 \\ \text {-No VPA } & 157 & 86.6 & \mathbf{1 . 3} & 10.8 & 1.3 & 0 \\ \text {-VPA } & 48 & 72.7 & \mathbf{1 0 . 9} & 14.6 & 2.1 & 0\end{array}$

PREG III Preg II - Malformed foetus

$\begin{array}{ccccccc}\text { No AEDS } & 2 & 50.0 & \mathbf{0} & 50.0 & 0 & 0 \\ \text { On AEDs } & 29 & 75.9 & \mathbf{6 . 9} & 13.8 & 3.4 & 0 \\ \text {-No VPA } & 19 & 84.2 & \mathbf{5 . 3} & 10.5 & 0 & 0 \\ \text {-VPA } & 10 & 60.0 & \mathbf{1 0 . 0} & 20.0 & 10.0 & 0\end{array}$

PREG III Preg II - Spontaneous miscarriage

$\begin{array}{lcccccc}\text { No AEDS } & 16 & 56.3 & \mathbf{0} & 37.3 & 6.3 & 0 \\ \text { On AEDs } & 85 & 63.5 & \mathbf{9 . 4} & 25.9 & 0 & 1.1 \\ \text {-No VPA } & 70 & 67.1 & \mathbf{4 . 3} & 27.1 & 0 & 1.4 \\ \text {-VPA } & 15 & 46.7 & \mathbf{3 3 . 3} & 20.0 & 0 & 0\end{array}$

Table 2: Foetal malformation rates in Pregnancy III related to the corresponding Pregnancy II outcomes that are themselves correlated with Pregnancy I outcomes in the same woman.

\begin{tabular}{|c|c|c|c|c|c|}
\hline \multirow{2}{*}{$\begin{array}{c}\text { Pregnancy I } \\
\text { Outcome }\end{array}$} & \multirow[t]{2}{*}{$\mathbf{N}$} & \multirow{2}{*}{$\begin{array}{c}\text { Pregnancy II } \\
\text { Outcome }\end{array}$} & \multirow[t]{2}{*}{$\mathbf{N}$} & \multicolumn{2}{|c|}{$\begin{array}{c}\text { Pregnancy III } \\
\text { Malformed Foetus }\end{array}$} \\
\hline & & & & $\mathbf{N}$ & $\%$ \\
\hline \multirow[t]{3}{*}{ Normal foetus } & 406 & Normal foetus & 75 & 3 & 4.0 \\
\hline & & Spontaneous abortion & 46 & 1 & 2.2 \\
\hline & & Malformed foetus & 9 & 0 & 0 \\
\hline Malformed foetus & 46 & Normal foetus & 12 & 1 & 8.3 \\
\hline
\end{tabular}




\begin{tabular}{lllllc} 
& & Malformed foetus & 4 & 1 & 25.0 \\
Spontaneous abortion & 74 & Normal foetus & 30 & 0 & 0 \\
\cline { 3 - 5 } & & Spontaneous abortion & 20 & 4 & 20.0
\end{tabular}

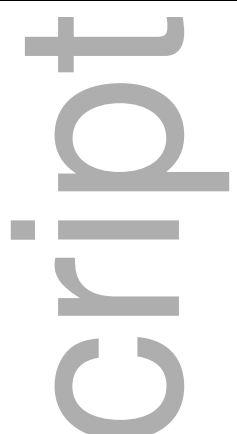

Table 3: The predominant malformation in the foetuses of women with at least 3 pregnancies and whose previous pregnancy had resulted in a spontaneous abortion or a malformed foetus, compared with the malformations in women whose previous pregnancy had yielded a normal foetus.

\begin{tabular}{|c|c|c|c|}
\hline \multirow{2}{*}{$\begin{array}{l}\text { Malformation / } \\
\text { Region Affected }\end{array}$} & \multicolumn{3}{|c|}{ Previous Pregnancy Outcome } \\
\hline & $\begin{array}{c}\text { Malformed } \\
\text { Foetus }\end{array}$ & $\begin{array}{c}\text { Spontaneous } \\
\text { Abortion }\end{array}$ & $\begin{array}{c}\text { Normal } \\
\text { Foetus }\end{array}$ \\
\hline & $\mathrm{N}=16$ & $\mathrm{~N}=11$ & $\mathrm{~N}=31$ \\
\hline Spina bifida & 5 & 2 & 4 \\
\hline Dandy-Walker & 1 & 0 & 0 \\
\hline Hydrocephalus & 0 & 0 & 2 \\
\hline Anenceph & 0 & 0 & 3 \\
\hline Cardiac & 3 & 2 & 5 \\
\hline Genital & 2 & 1 & 6 \\
\hline Facial clefts & 2 & 1 & 2 \\
\hline Face deformity & 0 & 0 & 2 \\
\hline Digits & 2 & 2 & 3 \\
\hline Others & 1 & 2 & 4 \\
\hline
\end{tabular}




\section{University Library}

\section{- M M N E R VA A gateway to Melbourne's research publications}

Minerva Access is the Institutional Repository of The University of Melbourne

Author/s:

Vajda, FJE;O'Brien, TJ;Graham, JE;Hitchcock, AA;Lander, CM;Eadie, MJ

Title:

Antiepileptic drugs, foetal malformations and spontaneous abortions

Date:

2017-03-01

Citation:

Vajda, F. J. E., O'Brien, T. J., Graham, J. E., Hitchcock, A. A., Lander, C. M. \& Eadie, M. J. (2017). Antiepileptic drugs, foetal malformations and spontaneous abortions. ACTA NEUROLOGICA SCANDINAVICA, 135 (3), pp.360-365. https://doi.org/10.1111/ane.12672.

Persistent Link:

http://hdl.handle.net/11343/291657 